\title{
MUSIC IMAGERY; A CONFESSION OF EXPERIENCE.
}

BY DR. ROBERT MACDOUGAL.

\section{Western Reserve University.}

The power of music to call up particularized images rests upon a process of indirect association which depends for its existence and character upon the individual genius and experience of the hearer. Music is not an intellectual instrument, as language is, having each element connected with a distinct object; and much of the æsthetic enjoyment which it affords is due to this very lack of definiteness in its content. The musical variations of human speech, as Spencer has observed, like the variation in amount and quality of gesturing, are expressive of passion and feeling. They interpret to a being susceptible of like emotion-and often transform in significance-the thoughtcontent of the words which they accompany. The function of music is to indicate or produce a mood rather than to communicate a set of definite concepts.

In speech, each element, the word, and each group of elements, the phrase or sentence, is connected with a distinct image or set of images; it means that, and should mean nothing else. And the perfect language is that one which has for each object one symbol and no more, a scientifically complete set of signs, without deficiency and without redundancy.

In music there are no such hard and fast lines of association. The note and the passage do not mean anything at all, as the phrase and the word do; and the æsthetic worth of music derives greatly from this plasticity of its symbols, and the wide subjective variation in their interpretation, which allows for the play of imagination and the influence of mood upon them. A piece of music, or certain passages of it, or even its single notes, may make us think of any one of a thousand things or experiences, just as the echo of a voice might, or the smell of a flower, or the sight of a glove or book; but the music does not mean 
these things as the word means the object for which it stands. It means them only because in some way it has become so associated with the past experience that at its occurrence that experience is called up.

The symbols of music might perfectly well be employed, as are the symbols of speech, to express definite particularized images. The variations in symbolism are endless; the sign may be an articulate sound as in speech, a graven or painted mark, as in writing and inscription, a flash of sunlight as in the heliograph, or the manipulation of the fingers, as in the language of the dumb. The intermittent sound of the electrical ticker, the swinging of the brakeman's lantern or the waving of his arms in train shifting, the red cross on the door in plaguestricken cities, the passes and foldings of the fan in a flirtation, these are all symbols having a definite intellectual content; and, though no such relation now exists, each note of the scale and each combination in a chord and composition into a phrase might be made to stand for some definite thought-object, with the result of producing a music-language.

For there are three forms of association which may connect the symbol with the object which it serves to call up. The first is by convention, the second by composition, and the third by analogy. Of the first class, as has already been said, human speech is the type. Its elements are arbitrary signs which by convention we have made to stand for certain objects and ideas, and which by custom we use to express our thought and describe our experience. There is no bond between them, either of likeness or natural connection, other than our will that it should be so. By composition I mean that association between two things which has arisen from their participation as elements in some common experience, by juxtaposition either in space or time. The smell of moist earth brings back a rainy day years ago, spent in tramping among the hills; the string of beads recalls the little playmate who wore them; the sight of a letter which he has forgotten to mail calls up the breakfast table and his wife's charges to the delinquent husband. Frequently in this form of association nothing of the original experience is recalled to mind, but only the mood which accompanied it, and 
occasionally this mood remains as an inexplicable whim of association, unsolvable by any assignable reason.

The sampler which violates every principle of good taste may yet be dear in spite of its hideousness, if it once hung upon the walls of a room we loved. And, surely, no redeeming feature can be conceived in the pungent, suffocating coal smoke which is beaten down into this city's streets on a muggy day; yet a gentleman has told me that to him the experience is always accompanied by an overtone of pleasure. He was unable, for a time, to account for this happy mood, but soon traced the cause to a similarity between the smell of Cleveland smoke and that of London, a city which he loved.

This form of association, both in the production of definite images and of a diffused tone of feeling, plays a great part in music. Perhaps in this consists its chief delight, apart from pure sensuous pleasure in the streaming and compounding of melodious sound, that through these fragmentary and evanescent associations it brings before the mind a procession of delightful images, or those still more characteristic moods which thrill and pass with each change in the orchestration. Suggestion by analogy or resemblance is still more widely employed in music to produce the desired effect. The ripple of water over stones, the singing of birds under the open sky, rain, wind, thunder and the ocean surf, the songs of a village festival, the clash and strife of a battle onset, all these are common musical effects, and such descriptive passages depend for success upon their direct imitative character. The images which they invoke are called up through the half-deceptive mimicry of the music, as the face of a friend is called up by the sound of his voice, or the appearance of the fluttering leaves, by the murmur of the breeze which passes through them. The association is simple and direct. Upon this imitative descriptive quality depend our battle pieces, our word music, our thunder-storms, as in Beethoven's Pastoral and the overture to Rossini's Tell. "All of a sudden the sky grows dark. The woods are silent; shudderings run over the surface of the lake. The water is ruffled. Nature seems to shrink within herself at the approach of the storm. It comes with mighty strides. The 
wind sways the tall firs; engulfs itself beneath the towering timber. A first lightning-flash rends the clouds, others follow; then the thunder roars, the hurricane is unchained in fury." Rossini describes all this-and can describe it only-by representative changes in the orchestration, from the subdued murmur of muted strings during the ominous hush of the woods preceding the outburst, to the tumultuous crash of music from all his instruments when the tempest is at its height. At the culmination of this harmonic storm the music stops. A moment of silence follows, in which we seem to feel the hush of exhausted nature, the storm dies away in a muffled rumbling from the drums, and the piece closes with the drowsy drip of water and the murmur of waterfalls swollen by the rain.

All our refined music is characterized by a much subtler and more elusive quality of imitation, in which spiritual passion and endeavor and the many moods of life are represented through a vocal symbolism assisted often by intricate intellectual associations, motifs and conventional cues. Take, for example, the overture to Tschaikovsky's ' 1812 ' in which the repulse from Moscow is described. The furious allegro which forms the main body of the piece is worked up stormily on the strings towards a full orchestration in which the martial notes of the cornets and horns rise high and clear amid the tempest from the strings and wood instruments. Winding in and out of this tumultuous chorus are fragments of the Marseillaise. This gradually becomes more complete until, at the moment when it is apparently about to dominate the passage, it breaks and is wholly lost in the thunder of the full orchestra. The victor is sufficiently indicated by the noble Russian hymn with which the overture closes. Hope, fear, tumult, the crash of battle, victory and defeat, together with the names of conqueror and conquered, are set forth here through imitative description eked out by motifs and conventional cues, such as Wagner has worked up into a well-defined system of symbols.

But there are other cases of visual imagery accompanying the hearing of music which are not thus easily referable to their sources, cases in which the image is apparently neither suggested by an analogy in the note or passage, nor called up by a 
conventional cue, nor assignable to any fact of habitual association or whim of fanciful interpretation. One lover of music has told me that frequently, as she listens to the music of an orchestra, an opening rose appears before her against a dark background. The phenomenon is apparently barren of association: there is the music, an auditory experience, and the rose, a visual experience; they appear together-but why, she cannot tell. The phenomenon is analogous to that of colored hearing and probably to a multitude of other experiences which occur unremarked to every individual. A more connected set of such sensuous images, in my own experiences, accompanied the hearing of one of Schubert's quartettes in the Sing-Akademie of Berlin some time ago. To this my long preamble has led and I shall transcribe it as it stands in the notes written the same evening after the performance. As I sat with closed eyes listening to the music a succession of visual images appeared, in almost unbroken series, sometimes unrelated, here and there broken for a moment, but at other times developing continuously into each other for the space of a minute or two, or even more.

The first number, from Mendelssohn's forty-fourth opus, was in progress when I entered, and I remained standing. No visual images accompanied this music. The second was from Beethoven's eighteenth opus, Quartette in A sharp, during the latter part of which visual images began to occur, especially during the andante movement. The third part of the program consisted of Schubert's Quartette in D minor, and it was during the allegro movement, with which the piece commences, that the imagery became a profuse and continuous accompaniment to the music.

For a few moments after the violins began to sound, though I attended as closely and with as much pleasure in the music as subsequently, no images appeared. My enjoyment was in the pure sensation of richly blending notes, and in the thrill of delight at each realized expectation, as note after note fell upon my ear. But in a few moments the music on the stage fell back to a secondary position. I saw suddenly before me, as I sat with closed eyes, a valley with gardens and shade-trees, and a slender rill of water winding down its center. The atmosphere 
was warm and hazy and the air was full of light and the humming of insects. And somewhere in the valley a voice was singing, a girl's voice, clear and tremulous. As I looked and listened, a troop of boys and girls tripped down the road. They were dressed in light colors, with flowers and wreaths upon their dresses, and carried tambourines and garlanded poles. As they came they were in continual graceful movement, dancing lightly in time with the music, shaking their instruments, waving their garlands and winding sinuously in and out among one another. Suddenly, as I watched, the valley grew dark and gloomy, the rich, warm hues of dresses and flowers began to fade away, and rain came down in great drops, heavier and heavier. The air was filled with the beating of the rain and the roar of water; the little stream in the trough of the valley swelled into a wide torrent; all the dancers dissolved away but one, a young girl, who remained irresolutely standing, surrounded on every side by the rushing water. Then a satyr appeared, who seized the girl in his arms and went off bounding through the water. After a few yards, as I watched his leaps and the white dress gleaming against the rocks, his hoof slipped upon the wet surface of a stone, and he fell headlong with his burden. At the same moment the whole scene faded from sight. Then I saw a forest and a lane passing through it, with an open space at the farther end, and the sun shining down into it. In the open space stood a tiny schoolhouse, and along the lane came a little girl in a short frock, with feet and shoulders bare; she was tripping as she came, in time with the music below me, and swinging a little satchel by a single strap. Then a group of children-boys and girls-came rushing down the lane like a gust of wind and disappeared as they approached me; then another, and another, and another, in quicker and stormier succession.

This all suddenly vanished and I sat in a theatre before an empty stage. In a moment a clown or dervish, wearing a wide, full gown of brown stuff, ran down before the footlights, danced a moment, and then began spinning on one toe like a teetotum. Then another joined him and another until, I think it was, five stood spinning giddily in a row ; and behind them 
another line of similarly whirling clowns appeared, until I grew dizzy watching.

All at once, however, I was again out under the blue sky, lying at full length on the bottom of a light canoe which drifted slowly before the breeze. I could see the clouds above me, and feel the rocking of the boat and hear the soft lapping of the waves against its side. Gradually the rocking became slower and more sluggish, as if the water of the lake were turning into treacle which grew thicker and thicker until the motion of the canoe wholly ceased. Then I sat up, and found myself fast frozen into the ice, near by the shore, on which a heavy forest grew. Just opposite me there was a break in the wood where a path led down to the water, and I could see the blue sky through the trees. As I looked, I heard a song, a song from a single voice, across the ringing, frosty air, and a grown boy came round the bend, swinging two water-pails which dangled from the ends of a heavy wooden yoke passing over his shoulders. He came down the bank, stopped at the edge of the water, and struck the corner of his pail sharply against the thin ice.

As the ice broke before the force of the blow this scene similarly vanished and I found myself standing in a great cathedral with long aisles stretching away from me until their farther ends were lost in gloom. Far down the church, or in some side chapel, I heard voices rising and falling in solemn cadences and gradually growing louder and more distinct; then slowly up the aisle filed a double row of monks, in long black gowns with their cowls flung back off their shaven heads. They approached until the foremost stood in full light a few yards from me; when, picking up their gowns with both hands at the sides and holding them wide apart as if dancing a minuet, they began capering noiselessly about. I saw their heavy shoes and rough wool stockings and wondered to see them dance so lightly, when, to my amazement, they rose bodily from the floor, changing form as they went, and passed up through the roof, a flock of swallow-like birds. Again a flock arose, and again, each mounting spirally in a gusty swirl of wings and disappearing, as steam disappears on a frosty day. 
Finally, a single bird was left far up in the sky, rocking slightly on poised wings but otherwise seeming to remain motionless.

As I watched it I heard a solitary, long-drawn, flute-like note sounding. And as it sounded I found myself on a seashore with cliffs behind me-I did not see them at all, but knew they were there-and a waste of rocking waves before me. It was night and the sky was dark and stormy. Far away at the horizon line there was a streak of cold yellow light. The air was filled with innumerable spirits all about, in ceaseless, intricate movement, whom I could not see, but whom I felt to be present on every hand. Across the water towards me, as I stood, came a group of voices, like a bit of flying cloud, but vocal, driven before the wind and melted about me, to be succeeded by another and yet another, and, I think, still a fourth.

With the fourth cloud of voices came a sudden break of strong red light in the sky, mounting rapidly from the horizon upward and spreading to right and left till that whole quarter of the heavens was in a glow. With the coming of the light arose a chorus of lusty young voices singing joyously.

Then suddenly it was bright day, and I stood in a road on the mountain side. There were great brown rocks on every side, and low trees here and there, and the sand on the road was red. There was no grass or flower anywhere about, nor any pretty thing, but all the features of the landscape were stern and grand. And close by me in the way was a young man who stood and looked up to the rocks on the mountain side; and once or twice he tried to climb, but could not. And I felt the strong endeavor and longing within him, but did not understand what it sought after, and I felt, too, the presence of an obstacle which could not be surmounted. Then he sat down on a stone by the roadside and laid his head upon his hands, and I felt the load upon his heart and grew hopeless, seeing his despair.

This also passed suddenly away, and I saw a wide old country road running through green fields, with great elms shadowing it; and near by an inn with a heavy wooden table under the tree before it. And down the road came working people, in ones and twos and threes, with rakes and hoes upon their shoulders. They walked slowly and were silent, and 
parted as they came near, some going to this house and others to that, the women passing at once in-doors, the men remaining outside putting things to rights, and talking occasionally among themselves. Darkness came on, lights were lit in the houses and the number of men to be seen became smaller and smaller. At last only one, an old man, remained, and as he passed into his house I followed him. It was a bare simple room, containing only a bed and an unpainted table with a single clumsy chair beside it. On the table stood a candle which the old man had just lighted, and a clock ticked high up on the wall. All the other lights had gone out in the village and everything was quiet and silent. The old man went here and there about the room, every moment moving more slowly and feebly, until at last he lay down to rest; once or twice he moved, then there were two long, even, soundless breaths, and all was still. The music had ceased.

The part which visual imagery plays in my psychological world depends greatly upon my physical condition. When thoroughly fresh and vigorous my thinking is slower, more logical, forced and schematic than when I am slightly tired. When actual weariness and languor set in, of course all mental exertion becomes painful and ineffective; but in the earlier stages of fatigue, before this final condition has been approached, a period of cerebral excitement occurs, often accompanied by. a slight frontal headache, in which my mental imagery becomes more varied and concrete than the normal. I feel an unusual brilliancy and fertility of suggestion; my mental scenery becomes less schematic and algebraic; comparisons and illustrations suggest themselves on every hand; thought proceeds by object images. At such times my sensation-memory also becomes unusually vivid and copious. There is no longer a dry, hard, logical way of conceiving things, but the sight and sound and smell of the things themselves, which seem to have been stored away in some solitary cell of the mind under lock and key, break forth from confinement and go rioting tumultuously across the stage in a chaos of imagery.

And on this particular occasion these conditions obtained. I had the night before finished a piece of work on which I had 
been closely engaged, and all that day was in a state of joyous elation at bringing it to a successful close. The day, too, had been filled with a succession of engagements, which demanded continuous activity of both mind and body, and after taking tea with a friend I had hurried directly to the academie, arriving there late, flushed, excited and slightly tired. The phenomenon of visual images accompanying the hearing of music has been, in my own experience, rare; on various occasions such imagery has arisen in my mind, but fragmentary, consisting of single, unrelated forms, which appeared on a dark background, remained visible a moment or two, and then suddenly vanished. And such images as appeared came sparsely during the course of the music, its effect during the intervals being of an altogether different kind. And the occurrence of visual musicimages has, among my personal acquaintance also, been rare rather than frequent. The phenomenon is in itself also a curious and interesting one. It is the more interesting to me in that I am usually a relatively poor visualizer. My memoryimages are neither copious, nor distinct, nor vivid in coloring. I find it difficult in most cases to recall how any group of things actually appeared; I cannot at all reproduce things in memory so as to be able to run over them again as if they stood once more before me. When I do succeed in gaining in this way a view of any group of things, it has none of the simultaneous wealth and variety of the concrete object-complex; I must recall element by element, and piece the whole together in a series of memory-syntheses. The images which do appear in distinct form before me are almost without exception pale in color and fleeting in character, being rapidly reinstated by successive efforts instead of remaining permanently before me any length of time through their own persistence. Even the faces of my most intimate friends sometimes escape me, and at best are usually remembered only by some individual feature and not at all in the rich objectivity of their actual presence. It is only a flashing remembrance of an eye-glance, or a fleeting smile, or a sudden memory of contour, or gesture, or even a single tone of voice which comes at my call; the sweet human variety of it continually escapes me. But not escapes me 
wholly; it is still present as a background and takes up the fragmentary ideas which visual memory affords and suffuses them with feeling, so that I have a very distinct and concentrated apperception of my friend-or whatever the object of memory may be-only it is not habitually a directly visual one. Sometimes I have found it utterly impossible to call up again the face of an acquaintance. No single attitude or expression, no line, or feature, or tone could I lay hold of by the closest endeavor stimulated by intense longing. When my mother died, for three weeks I could neither see her before me, nor remember how she looked, nor recall a single feature of her face. The memory, at the same time, was in other regards intensely vivid and strong. I have a friend of whom this is a typical experience. He has never been able in the slightest degree to recall his mother's face. He knows she is dark, with brown eyes, a firm chin, straight nose, face slightly lined, and hair plentifully sprinkled with gray. But he has never been able to put these analytic facts together in any sensational way, so as to see how she looks. He cannot even reconstruct his favorite professor's face when his back is turned.

My own enjoyment of suggested visual objects, I mean the form under which things which may be seen enter into my psychological world when remembered or otherwise suggested, is an indirect one. When I hear or read a description of any particular bit of landscape-for example, of standing on the shoulder of a hill and looking out over the valley and its nestling villages, of seeing a tempest in the mountains, or a snowstorm upon the plains, or of sweet, wet meadows lying bright in the slant sun after a sudden dash of rain-what I usually get is not a procession of visual events across the field of imagination, but a succession of emotional attitudes, the feeling which the beholding of the objects themselves would arouse, is called up directly by the description and not mediately through the suggestion of an interposed set of visual images. I get the glow, the thrill, the feeling of exultation, the stormy joy, the still serene pleasure, but not the diaphanous blue haze of the farther hill slopes, nor the ragged masses of thunder cloud torn by the mountain peaks, nor the swirling 
white mist of flying snow, nor the waving of wet leaves and shimmering of rain-drops in the sun. This is the most usual form of my experience, but by no means the invariable; visual images are frequently evoked, constantly so, indeed, but the typical way in which such things are represented to me is not through these visual objects, but through the emotional tone which they are suited to call up. But in the experience which I have described, to this syncopated form of suggestion there is added a further stage which involves an inversion of what $I$ suppose is the customary order of suggestion, namely, from intellectual perception through imaginative images to a mode of feeling. For here, apparently, out of the mood directly suggested by the music arose the particularized images which accompanied it. There was no conscious seeking after an interpretation of the music, no endeavor to find a series of objects or actions which, in some more or less fanciful way, would illustrate the character of the music. The scenes arose, the drama was acted with complete spontaneousness; I was as passive as if the figures had appeared before me on a real stage. Indeed they simulated a performance on the boards with great closeness, for the figures had all the vividness of the most distinct memory images, both in detail and coloring. So strong was the impression that, though the memory of the music is so completely gone that I should probably not recognize it again, yet several of the figures and scenes which accompanied it reappear now at the thought of the experience with almost their original intensity, although nearly two years have gone by since then.

I have not tried to trace out any close analogy between the quality of the individual passages and the character of their visual accompaniment. To do so it would be necessary to have a synchronous record of the music and its pictorial content, which would be wholly impossible to obtain. There is, at first blush, apparently a lack of any bond between the two. They occur together, as do the vowel and the color in chromasthesia, but with the like absence or obscurity of reason. Why, in colored hearing, is one letter accompanied by the sensation of red, another by that of yellow, a third by that of black? The thing 
is quite irrational; it can have its explanation only in some chance association peculiar to the individual, or in an original idiosyncrasy of the subject's make-up. And what intelligible connection can be imagined between the character of a piece of music and the slipping of a satyr's hoof upon a wet rock, or the antics of a group of mountebanks, or a school girl's swinging her satchel as she runs home from school? Apparently no more than between the music of which I have spoken previously and its evolving rose. Yet here and there the origin in my own experience of the images which arose is traceable, and in several others a certain connection may be imagined.

The experience is immensely more complex than that of colored hearing, and can scarcely be referred to its type. The intellectual processes whose results are involved are more intricate and highly developed than any which chromæsthesia demands, and fall in with a type which has found many illustrations in my experience. For instance, with the thought of one woman of my acquaintance comes habitually the half-sensational impression of Greek-fire and thunder, with that of another it is of a fountain and the tinkling of bells, of a third it is of a sepia etching. In all these three cases, whatever the mode of origination which established this association, there appears to me a decided fitness in the symbolism, a fitness which, of course, must be felt, and cannot in any exact way be either defined or defended.

In the experience which I have described something of the same nature can be traced. Several of the individual figures I can definitely locate. The singing monks find their original in the pilgrim chorus of Tannhäuser, a favorite scene of the opera which has always impressed me strongly; the lake with its floating canoe is the imaginative revival of an old habit of drifting idly in my canoe on a breezy day without sail or paddles; the troop of children have stepped out of some village festival or other on the stage; and the cloven-footed satyr is some fragment from a forgotten painting. There are several elements, too, which are repeated in the course of the experience. For example, the frolicking youths recur in another guise in the whirling dervishes, and again in the dancing monks; the vanishing rush of children down the lane is one in essence with the 
flight and disappearance of the transformed monks, and with the voices which sweep across the water and die away as they approach. And both of these groups of images are strongly suggestive of a rapid passage of music in a rising scale, such as actually occurred several times in the quartette. It is probable that some sort of such vague analogy accompanied the experience throughout, and that out of the feeling directly induced by the music the images arose through a congruity, at least temporarily felt, between mood and figure. The mood was the electrical atmosphere out of which developed the lightningflash of imagery. The influence of moods upon the character of our associations is at all times very great. As one tone of feeling or another becomes dominant, as in grief or joy, whole groups of objects, or aspects of life, are rendered so eminently congruous or incongruous that they are inevitably either dwelt on or excluded from contemplation. The existence of an intense mood, that is, will so raise the degree of excitability in a whole group of allied images that it requires but the slightest stimulation to touch them into activity. And here, out of the range of images from past experience, whose congruity made them possible subjects of suggestion, those actually arose into consciousness whose greater recency or vividness or superior fitness as symbols, rendered them momentarily the most easily excited. 